\title{
Depression among pregnant women and associated factors in Hawassa city, Ethiopia: an institution-based cross-sectional study
}

\author{
Bereket Duko ${ }^{1 *}$, Getinet Ayano ${ }^{2}$ and Asres Bedaso ${ }^{1}$
}

\begin{abstract}
Background: Depression is the most prevalent psychiatric disorder during pregnancy. It is not only common and chronic among women throughout the world but also principal source of disability in pregnant women. The scarce information and limited attention to the problem might aggravate the consequence of the problem and can limit the intervention to be taken. The objective of the study was to assess the prevalence and factors associated with depression among pregnant women in public health institutions, Hawassa, Ethiopia.

Methods: Institution based cross sectional study was conducted in May to July 2017. Pregnant women were selected by using systematic sampling technique. Data were collected through face-to-face interviews on sociodemographic, obstetric, psychosocial characteristics and depressive symptoms. Edinburgh Postnatal Depression Scale (EPDS) and Oslo Social Support Scale (OSS-3) were used to asses' depressive symptoms and social support respectively. Descriptive and logistic regression analyses were carried out.

Results: The mean age of the respondents was $23.82 \pm(S D=6.65)$ years. The prevalence of antenatal depression was $21.5 \%$. When we adjusted for the effect of potential confounding variables, being in age group of 20-30 years $[A O R=5.85$ (95\% Cl: $(3.70,10.14)]$, current pregnancy complication $[\mathrm{AOR}=4.98$ (95\% Cl: $(3.01,10.37)]$, unplanned pregnancy $[A O R=7.12$, (95\% Cl: $(3.12,9.63)]$, categories of stressors (LTE) Health risk [AOR $=1.76,(95 \%$ Cl: $(1.01,3.22)]$, previous history of depression [AOR $=2.76(95 \% \mathrm{Cl}:(1.94,6.75)]$, history of abortion [AOR $=1.52$, $(95 \% \mathrm{Cl}: 1.04,5.09)]$, history of still birth $[A O R=1.18,(95 \% \mathrm{Cl}: 1.08,2.91)]$, poor social support $[A O R=2.14,(95 \% \mathrm{Cl}: 1.49,3.11)]$ and poor baby father support $[\mathrm{AOR}=3.21(95 \% \mathrm{Cl}: 1.93,6.71)]$ were significantly associated with antenatal depression.
\end{abstract}

Conclusion: For early detection and appropriate intervention, antenatal clinics should develop screening tools for depression during the routine antenatal care.

Keywords: Depression, Antenatal care, Pregnant women, Ethiopia

\section{Plain English summary}

Among mental disorders that occur in pregnancy, depression has been now recognized as a global public health problem owing to its severity, chronic nature and recurrence as well as its negative impact on the general health of women and development of children. Thus, it is highly important to study the determinants of antenatal depression in pregnant mothers.

\footnotetext{
* Correspondence: berkole.dad@gmail.com

${ }^{1}$ Faculty of Health Sciences, College of Medicine and Health Sciences,

Hawassa University, P. O. Box 1560, Hawassa, Ethiopia

Full list of author information is available at the end of the article
}

Pregnant mothers were asked their background characteristics, the people with whom they get social support, experience of stressful life events during the 6 months period prior to assessment and antenatal depressive symptoms.

A total of 317 pregnant women were interviewed. Pregnant mothers age ranged from 15 to 45 years, the majority were married, non-employed and earned less than 57 USD per month. 117 (36.9\%) pregnant mothers had history of lost of new born child, 226 (71.3\%) had good family feeling on current pregnancy and 214 (67.5\%) had planned pregnancy.

(C) The Author(s). 2019 Open Access This article is distributed under the terms of the Creative Commons Attribution 4.0 International License (http://creativecommons.org/licenses/by/4.0/), which permits unrestricted use, distribution, and 
In this study, 68 (21.5\%) of pregnant mothers had antenatal depression. Mothers in the age group of 2030 years, educational status, history of abortion, history of lose new born child, previous pregnancy complication, current pregnancy complication, partner support, family feeling and planed pregnancy were factors which are significantly associated with antenatal depression with $p$-value of $<0.05$.

In summary, early detection and appropriate intervention is highly recommended. Antenatal clinics should develop screening tools for depression during the routine antenatal care.

\section{Background}

Depression is a common mental disorder which is characterized by loss of interest, depressed mood, and disturbance of sleep, psychomotor activity, and difficulty to concentrate, guilty feeling, easily tiredness and recurring thought of death wish [1]. Among psychiatric problems that occur in pregnancy, depression is a prevalent mental health problem affecting about one in five women worldwide $[2,3]$.

It has been now recognized as a global public health problem owing to its severity, chronic nature and recurrence as well as its negative impact on the general health of women and development of children [4, 5]. The prevalence of antenatal depression is estimated to be $15.6 \%$ in low -and middle-income countries although there is no evidence from $92 \%$ of the countries [3].

Depression during the prenatal period in associated with a range of fetal and obstetric problem and adverse developmental child outcome [6], and in low and middle income countries evidence suggests that its impact extend beyond psycho-social developmental delay to child health outcome [7].

Studies conducted in low and middle income countries also showed that there was a significance association between antenatal depression and poor infant outcome like low birth weight, preterm delivery or both, fetal growth restriction [8]. Pregnant women with depression were also more likely suffer from obstetrical complication such as pre -eclampsia, uterine irritability\& pregnancy induced hypertension [9].

Despite these known risk, depression during antenatal period was often not recognized and treatment rates were lower in pregnant than in non-pregnant women; even in well-resourced context [10]. It also affects the mother-infant interaction through its influence on the occurrence of post-natal depression [11].

Although depression has serious impact in pregnant mothers, per our literature review the research in this area is low. The aim of study was to determine the prevalence and factors associated with depression among pregnant mothers in Ethiopia.

\section{Methods}

\section{Study setting and population}

Institution based cross-sectional study was conducted from May to July 2017 at antenatal clinics in public health institutions in Hawassa, Ethiopia. Hawassa city, the capital of Southern Nations, Nationalities and Peoples Regional State (SNNPRS) which is located $273 \mathrm{KMs}$ South of Addis Ababa, Ethiopia. The city is subdivided into 8 sub cities having a population of 343,175 $(176,599 \mathrm{M}, 166,576 \mathrm{~F})$ residents [12]. There are two governmental hospitals and five urban health centers. Among the mentioned health institutions, two health centers and one public hospital were selected randomly for the study. Pregnant mothers were allocated to their study institutions proportionally and were included in the study using systematic sampling technique $(K=2)$. Three pregnant mothers were excluded from the study.

\section{Inclusion and exclusion criteria}

All pregnant women who had follow-up at their respective antenatal clinics were included in the study. Those who had severe form of mental illness that hinders their communication and critically ill women were excluded from the study.

\section{Data collection instruments}

Demographic variables were collected using semi-structured questionnaire. Depressive symptoms were assessed using Edinburgh Postnatal Depression Scale (EPDS). It is a 10 item questionnaire, scored from 0 up to 3 (higher score indicating more depressive symptoms), that has been validated for detecting depression in ante partum and postpartum samples in many countries. The instrument was validated in Addis Ababa for postpartum use and showed sensitivity of $84.6 \%$ and specificity of $77.0 \%$ at the cutoff score $7 / 8$ [13]. The cutoff point of EDPS among pregnant women is usually higher than postpartum women [14]. In this study, we used EPDS cutoff point of 13 to identify pregnant women with depressive symptom $[15,16]$. Those pregnant women who scored $>13$ were categorized as depressed women while pregnant women who scored below 13 were considered as non-depressed women [15]. Experience of stressful life events during the 6 months period prior to assessment was assessed using the List of Threatening Experiences (LTE) [17]. The 12 items were categorized into five categories namely health risks, loss of a loved one, relationship difficulties, income instability, and legal problems [18]. The LTE contains 12 categories of significant life events, for example relating to death of close persons, loss of relationships, imprisonment, and loss of valued object. These 12 categories accounted for two thirds of all events collected in the original development of the tool. It was reliable in the study (Cronbach's $\alpha=0.90$ ) [19]. Social support was measured by the Oslo 3-item Social Support Scale. Oslo 3-item social 
support scale is 3-item questionnaire commonly used to assess social support. It has the sum score scale ranging from 3 to 14 with three broad categories: "poor support" $3-8$, "moderate support" 9-11 and "strong support" 12-14. It was reliable in the study (Cronbach's $\alpha=0.88$ ). The social support scores were categorized into poor or no social support for scores less than nine. The scores from 9 to 14 were considered moderate to strong support and merged together as "yes" for social support [20].

\section{Data processing and analyses}

The coded data was checked, cleaned by entering into Epi Info version 7 and exported into Statistical Package for the Social Sciences (SPSS window version 22) for analysis. Descriptive statistics were employed to estimate the prevalence of antenatal depression. Binary logistic regression analysis was conducted to assess the relationship between each independent variable and dependent variable. The strength of association was measured by odds ratios with $95 \%$ confidence intervals. Statistical significance was declared at $P<0.05$.

\section{Results}

\section{Socio-economic and demographic characteristics}

A total of 317 pregnant women were included. The mean age of the clients was $23.82 \pm(\mathrm{SD}=6.65)$ years. The majority of participants were; 274 (86.4\%) married, 155 (48.9\%) Protestant, 202 (63.7\%) non-employed, 110 $(34.7 \%)$ of the respondents attended grade $11-12$ and $216(68.1 \%)$ earned less than 57 USD per month (Table 1).

\section{Obstetric and clinical characteristics}

Among the pregnant mothers, 110 (34.7\%) of them had history of abortion, 117 (36.9\%) had history of lost of new born child, 226 (71.3\%) had good family feeling on current pregnancy, 104 (32.8\%) had previous pregnancy complication, $214(67.5 \%)$ had planned pregnancy, 173 (54.3\%) had good partner support \& 105 (33.1\%) had current pregnancy complication (Table 2).

\section{Prevalence of antenatal depression}

The internal consistency of EPDS tool was acceptable (Cronbach's $\alpha=0.87$ ). The prevalence of antenatal depression ( $\geq 13$ on EPDS score) was 68 (21.5\%) (95\% CI: $17.05,25.10)$.

\section{Factors associated with antenatal depression}

Finding from logistic regression analysis showed that age of the mother, educational status, history of abortion, history of lost of new born child, previous pregnancy complication, current pregnancy complication, partner support, family feeling, poor social support and planned pregnancy were significantly associated with depression
Table 1 Frequency distribution of Socio-demographic and socioeconomic factors among pregnant women at Public health institutions in Hawassa City, Ethiopia, $2017(n=317)$

\begin{tabular}{|c|c|c|c|}
\hline Variable & Category & Frequency $(n)$ & Percent (\%) \\
\hline \multirow[t]{3}{*}{ Age } & $15-19$ & 108 & $34.1 \%$ \\
\hline & $20-30$ & 171 & $53.9 \%$ \\
\hline & $>30$ & 38 & $12.0 \%$ \\
\hline \multirow[t]{3}{*}{ Marital status } & Married & 274 & $86.4 \%$ \\
\hline & Divorced & 34 & $10.7 \%$ \\
\hline & Widowed & 9 & 2.8 \\
\hline \multirow[t]{4}{*}{ Religion } & Protestant & 155 & $48.9 \%$ \\
\hline & Orthodox & 99 & $31.2 \%$ \\
\hline & Muslim & 43 & $13.6 \%$ \\
\hline & Catholic & 20 & $6.3 \%$ \\
\hline \multirow[t]{5}{*}{ Education } & No formal education & 21 & $6.6 \%$ \\
\hline & Grade 1-8 & 41 & $12.9 \%$ \\
\hline & Grade 9-10 & 83 & $26.2 \%$ \\
\hline & Grade 11-12 & 110 & $34.7 \%$ \\
\hline & College/ university & 62 & $19.6 \%$ \\
\hline \multirow{3}{*}{$\begin{array}{l}\text { Occupational } \\
\text { status }\end{array}$} & Government employee & 34 & $10.7 \%$ \\
\hline & Private employee & 81 & $25.6 \%$ \\
\hline & Housewives & 202 & $63.7 \%$ \\
\hline \multirow[t]{3}{*}{ Monthly income } & $<57$ USD & 216 & $68.1 \%$ \\
\hline & 57-96 USD & 26 & $8.2 \%$ \\
\hline & $>96$ USD & 75 & $23.7 \%$ \\
\hline
\end{tabular}

with $p$-value of $<0.05$. However, occupational status, history of chronic disease and history of low birth weight were not associated with depressive symptoms (Table 3).

\section{Discussion}

Based on Edinburgh Postnatal Depression Scale, the prevalence of depression among pregnant women attending antenatal clinics in the current study was $21.5 \%$ (95\% CI: 17.05-25.10). This finding is in line with the study conducted in Nigeria [21], India [22], Ethiopia [9], Brazil [23], and rural Bangladesh [24]. On the other hand, the current finding is lower than the study conducted in South Africa [25], Jamaica [26] and London [27]. However, the finding is higher than the study conducted in Brazil [28], India [29], and Ethiopia [30]. The variation in prevalence might be due to methodological differences between studies \& study setting (institution vs community based). The other difference might be due difference in data measurement tools. Our study used Edinburg postnatal depression scale while others used patient health questionnaire item nine (PHQ9), Hamilton depression scale (HDS) and beck depression inventory scale (BDI). The socio demographic and 
Table 2 Obstetrics and Social support factors among pregnant women at public health institutions at Hawassa City, Ethiopia, $2017(n=317)$

\begin{tabular}{llll}
\hline $\begin{array}{l}\text { Obstetric History and social } \\
\text { support characteristics }\end{array}$ & & Frequency & Percent $\%$ \\
\hline History of abortion & Yes & 98 & $34.7 \%$ \\
History of loss of new born & Yes & 219 & $65.3 \%$ \\
& No & 200 & $36.9 \%$ \\
Current pregnancy complication & Yes & 105 & $33.1 \%$ \\
& No & 212 & $66.9 \%$ \\
Pervious pregnancy complication & Yes & 104 & $32.8 \%$ \\
& No & 213 & $67.2 \%$ \\
Baby father support & Poor & 141 & $54.6 \%$ \\
Unplanned pregnancy & Good & 176 & $45.4 \%$ \\
Family feeling about & Yes & 103 & $32.5 \%$ \\
current pregnancy & No & 214 & $67.5 \%$ \\
Categories of stressors & Good feeling & 226 & $71.3 \%$ \\
(LTE) Health risk & Poor feeling & 91 & $28.7 \%$ \\
Social support & Yes & 120 & $37.9 \%$ \\
History of still birth & No & 197 & $62.1 \%$ \\
\hline & Good & 176 & $55.5 \%$ \\
& Poor & 141 & $44.5 \%$ \\
& Yes & 93 & $28.9 \%$ \\
& No & 224 & $71.1 \%$ \\
\hline
\end{tabular}

economic differences might also attribute for the difference in prevalence of antenatal depression between this study and the studies from other countries of the world.

Regarding age, being in age group of $20-30$ years is 5.85 times $[\mathrm{AOR}=5.85$ (95\% CI: $(3.70,10.14)]$ more likely to have antenatal depression than those in age group of $15-19$ years. This is in line with other studies conducted in Nigeria [21] and in South Africa [25]. This might be supported by the fact that depression is commonly onset in the early 20's of the life and most of the study participants were housewives who are financially dependent on their partner that could precipitate the occurrence of depression in this age group.

Having current pregnancy complication is 4.98 times [AOR $=4.98$ (95\% CI: $(3.01,10.37)]$ more likely to have depression. This finding is in line with other previous studies in low income countries [3, 30]. This might be due to the fact having complication by itself minimize their satisfaction to their life and this will impact their psychosocial wellbeing which is one of the possible causes of depression.

Like other similar studies, pregnant women who did not plan their current pregnancy 7.12 times $[\mathrm{AOR}=7.12$ (95\% CI: $(3.12,9.63)]$ more likely to have depression when compared to those who planned their pregnancy $[3,23,9,15,30]$. It is established fact that pregnancy could cause physical, hormonal and psychological changes in pregnant mothers as a result it needs prior plan and preparation. Some studies in low-and-middle income countries showed that unplanned pregnancy is risk factor for antenatal depression.

The experience of stressful event related to injury and illness during the 6 months prior to the interview was 1.76 times $[\mathrm{AOR}=1.76 \quad(95 \% \mathrm{CI}:(1.01,3.22)]$ more likely to have antenatal depression. This finding was in agreement with other study findings [30, 31]. Having stressful situation prior to pregnancy or during pregnancy might predicted higher depression in the current pregnancy.

Having previous history of depression has significant association antenatal depression. Pregnant women who had past history of depression were 2.76 times [AOR = 2.76 (95\% CI: $(1.94,6.75)]$ more likely to have antenatal depression as compared to those who had no history of past depression. This might be due to pregnant mothers are more biologically vulnerable to depression and in addition to this hormonal changes during pregnancy might precipitate previous depression or their psycho-social context may make them vulnerable to recurrent depression [3, 9, 24, 30, 32-34].

Previous history of abortion has significant association with antenatal depression. Those pregnant mothers who had previous history of abortion were 1.52 times [AOR $=1.53$ (95\% CI: $(1.04,5.09)]$ more likely to have depression. This finding was in-line with a study in Ethiopia [30] and Brazil [35]. This might be due to the thought of having abortion in the current pregnancy could result stressful situation that impose them to depression.

The study also revealed that, having history of still birth was 1.18 times $[\mathrm{AOR}=1.18$ (95\% CI: $(1.08,2.91)$ ] more likely to have antenatal depression. This is highly supported by other studies [3, 30, 36]. Pregnancies that occur after still birth often be caught with a change of emotions that osculates from fear and guilt to joy and relaxations. This might precipitate the obsession of residual sadness, not talking about it and withdraws the past events finally end up with isolation that might predispose to depression [37].

Regarding to social support, antenatal depression was significantly higher among pregnant mothers who had poor social support than women who had good social support. This might be due to having poor social support may lead to increased psychological distress and on the other hand, good social support is vital for those with good health in prevention of depression.

Lastly, women who had poor baby's father support were found to be a statistically significant. This could be due to depressed women might assume 
Table 3 Factors associated with antenatal depression among pregnant women attending antenatal clinics in public health institutions in Hawassa, $2017(n=317)$

\begin{tabular}{|c|c|c|c|c|c|}
\hline \multirow[t]{2}{*}{ Characteristics } & & \multicolumn{2}{|c|}{ Depression } & \multirow[t]{2}{*}{$\mathrm{COR}$ at $95 \% \mathrm{Cl}$} & \multirow[t]{2}{*}{ AOR at $95 \% \mathrm{Cl}$} \\
\hline & & $\overline{Y e s}$ & No & & \\
\hline \multirow[t]{3}{*}{ Age in years } & Age group 15-19 & 11 & 97 & 1 & 1 \\
\hline & Age group 20-30 & 42 & 129 & $2.87(1.89,7.17)$ & $5.85(3.70,10.14)^{*}$ \\
\hline & Age group $>30$ & 16 & 22 & $6.41(1.07,9.95)$ & $3.91(0.83,8.44)$ \\
\hline \multirow[t]{2}{*}{ Current pregnancy complication } & Yes & 55 & 50 & $15.58(11.02,21.55)$ & $4.98(3.01,10.37)^{*}$ \\
\hline & No & 14 & 198 & 1 & 1 \\
\hline \multirow[t]{2}{*}{ Unplanned pregnancy } & Yes & 46 & 57 & $6.70(4.51,11.93)$ & $7.12(3.12,9.63)^{*}$ \\
\hline & No & 23 & 191 & 1 & 1 \\
\hline \multirow[t]{2}{*}{ Categories of stressors (LTE) Health risk } & Yes & 12 & 108 & $2.32(1.46,5.48)$ & $1.76(1.01,3.22)^{*}$ \\
\hline & No & 9 & 188 & 1 & 1 \\
\hline \multirow[t]{2}{*}{ Previous history of depression } & Yes & 13 & 35 & $4.89(3.31,8.27)$ & $2.76(1.94,6.75)^{* *}$ \\
\hline & No & 19 & 250 & 1 & 1 \\
\hline \multirow[t]{2}{*}{ History of abortion } & Yes & 17 & 81 & $1.38(1.01,4.51)$ & $1.52(1.04,5.09)^{*}$ \\
\hline & No & 29 & 190 & 1 & 1 \\
\hline \multirow[t]{2}{*}{ History of still birth } & Yes & 15 & 78 & $1.34(1.14,3.41)$ & $1.18(1.08,2.91)^{*}$ \\
\hline & No & 28 & 196 & 1 & 1 \\
\hline \multirow[t]{2}{*}{ Social support } & Poor & 24 & 94 & $3.37(1.72,6.85)$ & $2.14(1.49,3.11)^{* *}$ \\
\hline & Good & 14 & 185 & 1 & 1 \\
\hline \multirow[t]{2}{*}{ Baby father support } & Good & 17 & 159 & 1 & 1 \\
\hline & Poor & 62 & 79 & $7.34(3.52,9.68)$ & $3.21(1.93,6.71)^{*}$ \\
\hline
\end{tabular}

1 -Reference category, ${ }^{*}$ - statistically significant $-P$-value $<0.05,{ }^{*}{ }_{-}$- statistically significant $-P$-value $<0.01$

that the support they receive is not sufficient enough or minimal. This finding is in line with other studies $[3,9,16,24,25]$.

\section{Conclusion}

In the current study, prevalence of depression among pregnant women attending antenatal clinics was high. Age group of 20-30, current pregnancy complication, unplanned pregnancy, categories of stressors (LTE) health risk, previous history of depression, history of abortion, history of still birth, poor social support and poor baby father support were significantly associated with antenatal depression. For early detection and appropriate intervention, antenatal clinics should develop screening tools for depression during the routine antenatal care.

\section{Strength and limitation of study}

The study incorporated possible variables and used standardized measurement scales. However, being a cross-sectional study design; it did not allow establishing a temporal relationship between depression and other statistically significant variables. In addition, the study only included pregnant mothers who were started antenatal care follow up at health facilities this might over or under estimate the finding.

Abbreviations

EPDS: Edinburg postnatal depression scale; LTE: Life threating events; OSS3: Oslo Social Support Scale item 3

\section{Acknowledgements}

The authors appreciate respective study institutions, data collectors and study participants for their cooperation in providing the necessary information.

\section{Funding}

No specific funding received for this study.

Availability of data and materials

All relevant data are within the paper.

Authors' contributions

$\mathrm{BD}$ conceived the study and was involved in the study design, reviewed the article, analysis, report writing and drafted the manuscript. GA \& AB was involved in drafting the manuscript. All authors read and approved the final manuscript.

\section{Ethics approval and consent to participate}

Ethical clearance was obtained from the College of medicine and health sciences, Hawassa University, Ethiopia. Oral informed consent was obtained after they were introduced to the purpose of the study and informed about their rights to interrupt the interview at any time. Confidentiality was maintained by using anonymous questionnaire and privacy was assured. 


\section{Consent for publication}

Not applicable

\section{Competing interests}

The authors declare that they have no competing interests.

\section{Publisher's Note}

Springer Nature remains neutral with regard to jurisdictional claims in published maps and institutional affiliations.

\section{Author details}

${ }^{1}$ Faculty of Health Sciences, College of Medicine and Health Sciences, Hawassa University, P. O. Box 1560, Hawassa, Ethiopia. ${ }^{2}$ Department of reseaarch and training, Amanuel Mental Specialized Hospital, Addis Ababa, Ethiopia.

Received: 11 November 2018 Accepted: 13 February 2019

Published online: 28 February 2019

\section{References}

1. Gotlib IH, Whiffen VE, Mount JH, Milne K, Cordy NI. Prevalence rates and demographic characteristics associated with depression in pregnancy and the postpartum. J Consult Clin Psychol. 1989;57(2):269-74.

2. Pereira PK, Lovisi GM, Pilowsky DL, Lima LA, Legay LF. Depression during pregnancy: prevalence and risk factors among women attending a public health clinic in Rio de Janeiro, Brazil. Cad Saude Publica. 2009;25:2725-36.

3. Fisher J, Cabral de Mello M, Patel V, Rahman A, Tran T, et al. Prevalence and determinants of common perinatal mental disorders in women in low- and lower-middle-income countries: a systematic review. Bull World Health Organ. 2012;90:139G-49G.

4. Prince M, Patel V, Saxena S, Maj M, Maselko J, et al. No health without mental health. Lancet. 2007:370:859-77.

5. D M C., D L (2006) Projections of Global Mortality and Burden of Disease PLoS Med 3 .

6. Alder J, Fink N, Bitzer J, Hosli I, Holzgreve W. Depression and anxiety during pregnancy: a risk factor for obstetric, fetal and neonatal outcome? A critical review of the literature. J Matern Fetal Neonatal Med. 2007;20:189-209.

7. World Health organization (WHO). Mental health aspect of women's reproductive health, a global review of literature. Geneva: 2009.

8. PHC RONDO, FERREIRA RF, NOGUEIRA F, RIBEIRO MCN. Maternal psychological stress and distress as predictors of low birth weight, prematurity and intrauterine growth retardation. Eur J Clin Nutr. 2003;57:266-72.

9. Biratu A, Haile D. Prevalence of antenatal depression and associated factors among pregnant women in Addis Ababa, Ethiopia: a cross-sectional study. Reprod Health. 2015;12:99.

10. Vesga-López O, Blanco C, Keyes K, Olfson M, Grant BF, Hasin DS. Psychiatric disorders inpregnant and postpartum women in the United States. Arch Gen Psychiatry. 2008;65(7):805-15

11. Sawyer A, Ayers S, Smith H. Pre-and postnatal psychological wellbeing in Africa: a systematic review. J Affec Disord. 2010;123(1):17-29.

12. Hawassa city administration report of 2014, https://www.hawassafinance. com/files/2006_profile.pdf. Accessed Mar 2017.

13. Tesfaye M, Hanlon C, Wondimagegn D, Alem A. Detecting postnatal common mental disorders in Addis Ababa, Ethiopia: validation of the Edinburgh postnatal depression scale and Kessler scales. J Affect Disord. 2010;122(1-2):102-8.

14. Gibson J, McKenzie-McHarg K, Shakespeare J, Price J, Gray R. A systematic review of studies validating the Edinburgh postnatal depression scale in antepartum and postpartum women. Acta Psychiatr Scand. 2009;119:350-64.

15. Dibaba $Y$, Fantahun $M$, Hindin MJ. The association of unwanted pregnancy and social support with depressive symptoms in pregnancy: evidence from rural southwestern Ethiopia. BMC Pregnancy Childbirth. 2013;13:135.

16. Senturk V, Abas M, Berksun O, Stewart R. Social support and antenatal depression in extended and nuclear family environments in Turkey: a crosssectional survey. BMC Psychiatry. 2011;11:48

17. Brugha T, Bebbington $P$, Tennant C, Hurry J. The list of threatening experiences: $a$ subset of 12 life event categories with considerable long-termcontextual threat. Psychol Med. 1985;15:189-94.

18. Jenkins R, Mbatia J, Singleton N, White B. Common mental disorders and risk factors in UrbanTanzania. Int J Environ Res Public Health. 2010;7:2543-58.
19. Montón-Franco C, Josefa G, Gómez-Barragán M, Sánchez-Celaya M, Ángel Díaz-Barreiros $M$, et al. Psychometric propertiesof the list of threatening experiences-LTE and its association with psychosocial factors and mental disorders according to different scoring methods. J Affect Disord. 2013:150: 931-40.

20. Dalgard OS, Dowrick C, Lehtinen V, Vazquez-Barquero JL, Casey P, et al. Negative life events, social supportand gender difference in depression: a multinational community survey with data from the ODIN study. Soc Psychiatry Psychiatr Epidemiol. 2006:41:444-51.

21. Thompson O, Ajayi IO. Prevalence of antenatal depression and associated risk factors among pregnant women attending antenatal clinics in Abeokuta north local government area, Nigeria. Depress Res Treat. 2016;2016:4518979 15 pages.

22. Mina S, Balhara Y, Verma R, Mathur S. Anxiety and Depression amongst the urban females of Delhi in ante-partum and post-partum period. Delhi Psychiatry Journal. 2012;15:2.

23. Faisal-Cury A, Menezes P, Araya R, Zugaib M. Common mental disorders during pregnancy: prevalence and associated factors among low-income women in São Paulo, Brazil. Arch Women Ment Health. 2009:120:335-43.

24. Nasreen HE, Kabir ZN, Forsell Y, Edhborg M. Prevalence and associated factors of depressive and anxiety symptoms during pregnancy: a population based study in rural Bangladesh. BMC Womens Health. 2011;11:22.

25. Hartley M, Tomlinson M, Greco E, Comulada WS, Stewart J, Roux I, et al. Depressed mood in pregnancy: prevalence and correlates in two Cape Town peri-urban settlements. Reprod Health. 2011;8:9.

26. Wissart J, Parshad O, Kulkarni S. Prevalence of pre- and postpartum depression in Jamaican women. BMC Pregnancy Childbirth. 2005;5:15.

27. Plant DT, Pariante CM, Sharp D, Pawlby S. Maternal depression during pregnancy and offspring depression in adulthood: role of child maltreatment. Br J Psychiatry. 2015;207:213-20.

28. Benute GRG, Nomura RMY, Reis JS, Junior RF, de Lucia MCS, Zugaib M. Depression during pregnancy in women with a medical disorder: risk factors and perinatal outcomes. Clinics. 2010;65(11):1127-31.

29. Ajinkya S, Jadhav PR, Srivastava NN. Depression during pregnancy: prevalence and obstetric risk factors among pregnant women attending a tertiary care hospital in Navi Mumbai. Ind Psychiatry J. 2013;22(1):37-40.

30. Bisetegn TA, Mihretie G, Muche T. Prevalence and predictors of depression among pregnant women in Debretabor town, Northwest Ethiopia. Dang Y, ed. PLoS One. 2016;11(9):e0161108.

31. Rallis S, Skouteris H, McCabe M, Milgrom J. A prospective examination of depression, anxiety and stress throughout pregnancy. Women Birth. 2014; 27:e36-42.

32. Manikkam L, Burns JK. Antenatal depression and its risk factors: an urban prevalence study in KwaZulu-Natal. S Afr Med J. 2012;102(12):940-4.

33. Dayan J, Creveuil C, Dreyfus M, Herlicoviez M, Baleyte J-M, O'Keane V. Developmental model of depression apply to prenatal depression: role of present and past life events, past emotional disorders and pregnancy stress. PLoS One. 2010:5(9):e12942

34. Rahman A, Fisher J, Bower P, Luchters S, Tran T, Yasamy MT, et al. Interventions for common perinatal mental disorders in women in low-and middle-income countries: a systematic review and meta-analysis. Bull World Health Organ. 2013;91:593-601.

35. Pereira PK, Vieira CL, Santos JF, Lima LA, Legay LF, et al. Adverse perinatal and infant outcomes among children born to mothers with major mental disorders in a psychiatric hospital in Rio de Janeiro, Brazil. Cad Saude Publica 2014;30:1654-66.

36. Adewuya AO, Ola BA, Aloba OO, Dada AO, Fasoto OO. Prevalence and correlates of depression in late pregnancy among Nigerian women. Depress Anxiety. 2007:24:15-21.

37. National institute of health, Stillbirth may increase women's long term risk for depression, 2015 (February), https://www.nih.gov/news-events/newsreleases/stillbirth-may-increase-womens-long-term-risk-depression. Accessed Sept 2017. 